\title{
A 3D Hierarchical Pancake-Like Porous Carbon Nitride for Highly Enhanced Visible-Light Photocatalytic $\mathrm{H}_{2}$ Evolution
}

\author{
Xiaobin Qiu, Lingfang Qiu *, Mengfan Ma, Yingying Hou and Shuwang Duo *D \\ Jiangxi Key Laboratory of urfacSe Engineering, Jiangxi Science and Technology Normal University, \\ Nanchang 330013, China; xbluyin@126.com (X.Q.); MF1783975@126.com (M.M.); \\ hyy18170401838@163.com (Y.H.) \\ * Correspondence: qlf1108@163.com (L.Q.); swduo@imr.ac.cn (S.D.)
}

Received: 26 November 2019; Accepted: 2 January 2020; Published: 4 January 2020

check for updates

\begin{abstract}
Polymeric carbon nitride is a fascinating visible-light-response metal-free semiconductor photocatalyst in recent decades. Nevertheless, the photocatalytic $\mathrm{H}_{2}$ efficiency is unsatisfactory due to the insufficient visible-light harvesting capacity and low quantum yields caused by the bulky structure seriously limited its applications. To overcome these defects, in this research, a 3D hierarchical pancake-like porous carbon nitride (PPCN) was successfully fabricated by a facile bottom-up method. The as-prepared photocatalyst exhibit enlarged surface area, enriched reactive sites, improved charge carrier transformation and separation efficiency, and expanded bandgap with a more negative conduction band towardan enhanced reduction ability. All these features synergistically enhanced the photocatalytic $\mathrm{H}_{2}$ evolution efficiency of $3 \%$ Pt@PPCN $\left(430 \mu \mathrm{mol} \mathrm{g}^{-1} \mathrm{~h}^{-1}\right)$ under the visible light illumination $(\lambda \geq 420 \mathrm{~nm}$ ), which was nine-fold higher than that of 3\% Pt@bulk $\mathrm{C}_{3} \mathrm{~N}_{4}(\mathrm{BCN})\left(45 \mu \mathrm{mol} \mathrm{g}{ }^{-1} \mathrm{~h}^{-1}\right)$. The improved structure and enhanced photoelectric properties were systematically investigated by different characterization techniques. This research may provide an insightful synthesis strategy for polymeric carbon nitride with excellent light-harvesting capacity and enhanced separation of charges toward remarkable photocatalytic $\mathrm{H}_{2}$ for water splitting.
\end{abstract}

Keywords: pancake-like porous carbon nitride; bottom-up method; water splitting; visible light photocatalyst

\section{Introduction}

With fossil fuel reserves dwindling every day, energy shortage and environmental pollution issues have become increasingly prominent. Developing clean and renewable energy sources is urgent to meet the sustained growth in energy demand [1-6]. Since the discovery of the Honda-Fujishima effect in 1972 [7], photocatalytic hydrogen evolution reaction (HER) through water splitting has gained considerable attention due to its enormous potential to convert renewable solar energy to clean sustainable energy [8-12]. Researchers have devoted a significant amount of effort to investigate more effective photocatalytic systems for hydrogen evolution via photocatalytic water splitting [13-16]. Among multitudinous proposed semiconductor photocatalysts, polymeric carbon nitride (CN) has been considered promising for visible-light driven hydrogen evolution due to its tunable bandgap, low cost, earth-abundant nature, nontoxicity, facile preparation, being environmentally benign, and its remarkable physical and chemical stability [17-22]. Unfortunately, the photocatalytic performance of bulky CN was severely limited, resulting from the small specific surface area, large recombination rates of photo-excited electron-hole pairs, weak light-harvesting capacity, and inadequate catalytic active sites [23-28]. To address these shortcomings, many strategies have been developed, such as heteroatom 
doping [29,30], electronic structure modulation [31,32], nano-structuring [33,34], dye sensitization [35-37], and heterojunction construction [38-41]. Among them, nano-structuring is considered one of the most efficient and accessible strategies, as the enlarged specific surface area simultaneously abundant and quality active sites are not only favorable to the transfer of photo-excited charge carriers but also shortened the diffusion length for both ions and electrons [42,43]. On the other hand, the nano-structuring designed materials commonly exhibit the quantum confinement effect [24] with an enlarged electronic bandgap would be favorable to an enhanced redox ability toward photocatalytic reaction, promoting the quality and quantity of photo-induced charge carriers to some extent.

The nanostructural $\mathrm{CN}$ can be achieved by many methods. template-assistance strategies, top-down methods, and hydrothermal approaches have been regarded as representative and impelling strategies to fabricate multidimensional $\mathrm{CN}[44,45]$. Nevertheless, these methods have many unsatisfactory deficiencies, such as a shortage of template species, large time consumption, and being environmentally unfriendly, resulting from the introduction of hazardous reagents, challenging the removal of the byproducts [46,47]. In contrast, the highly efficient photocatalysis materials benefited from the improved structure and accelerated the separation efficiency of photo-induced charge carriers, which is relatively convenient to obtain by a facile bottom-up method [48,49].

Porous carbon nitride as a photocatalyst was introduced by Kang et al. Nevertheless, the material showed undesirable photocatalytic performance with a poor quantum efficiency of $\sim 0.5 \%$. Rahman et al. improved it to some extent, which reached a benchmark quantum efficiency of $\sim 6 \%[50,51]$. The synthesized photocatalyst exhibited similar structure compared to that synthesized by Rahmanetal. While the PPCN presented a higher quantum efficiency of $\sim 19 \%$.In this work, we report a low-cost and straightforward bottom-up method for the production of hierarchical pancake-like porous carbon nitride, the typical synthesis procedure is presented in Scheme 1. Typically, the cyanuric acid-melamine complex, which is suitable for controlling molecular self-assembly [52], was firstly synthesized. Then, ethanol and glycerol intercalated into the framework of the precursor. Next, a thermal-induced exfoliation and polycondensation process was performed to obtain the resultant products. The as-synthesized PPCN exhibited unique hierarchical pancake-like porous morphology structure and remarkable photoelectric properties. As expected, by virtue of an enlarged specific surface area up to $79.663 \mathrm{~m}^{2} \mathrm{~g}^{-1}$, enhancing the light-harvesting capacity, and enriching the reactive sites, the hierarchical porous architecture revealed a highly efficient photocatalytic $\mathrm{H}_{2}$ evolution efficiency for water splitting under visible light irradiation $(\lambda \geq 420 \mathrm{~nm})$, which is about nine-fold higher than that of the bulk carbon nitride (BCN). Various characterization approaches were performed to investigate the typical structure formation mechanism and the photoelectric properties of PPCN for the remarkably enhanced hydrogen evolution efficiency.

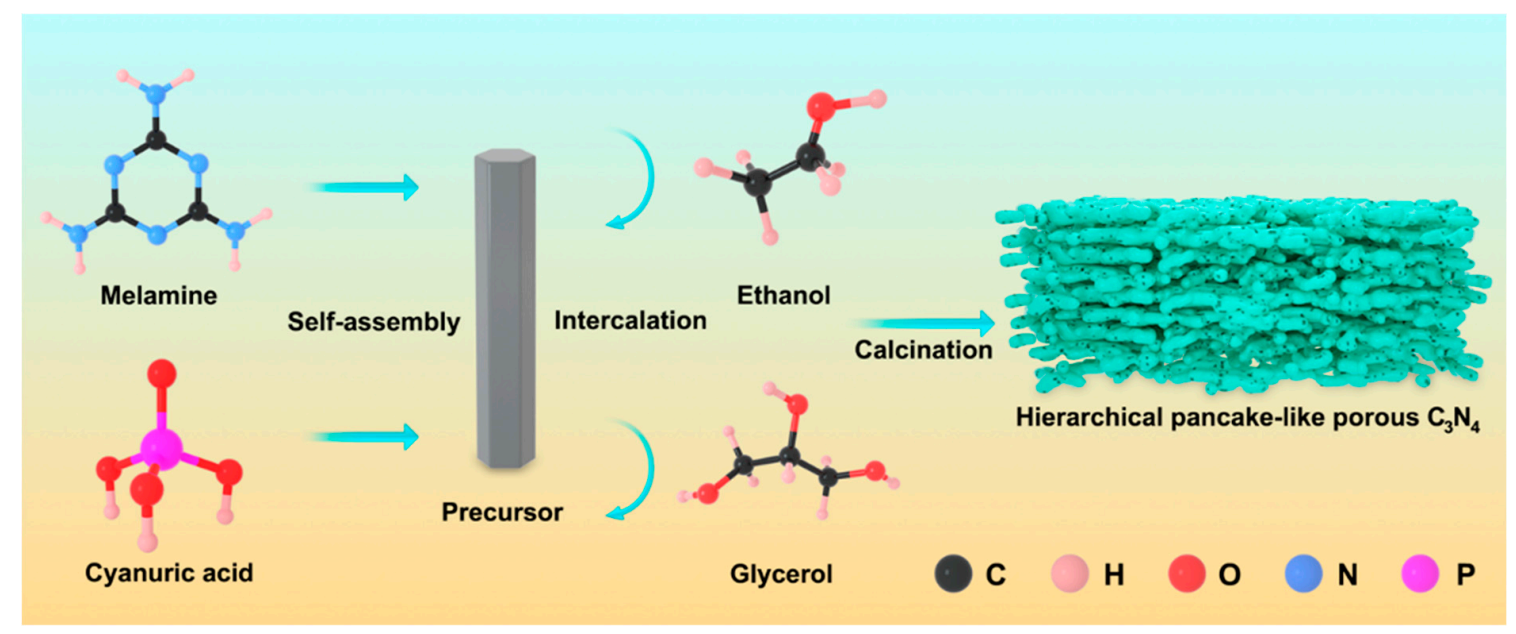

Scheme 1. Schematic illustration of hierarchical pancake-like porous $C_{3} N_{4}$ formation. 


\section{Results and Discussion}

\subsection{Morphology and Structure Characterization}

The morphologies of BCN and PPCN were investigated via SEM and TEM. It can be seen that BCN appears as a large solid block material (Figure 1a) with seriously agglomerated structure. The light absorption, charge transport, and mass immigration were severely restrained owing to this bulky structure. In contrast, a 3D hierarchical pancake-like porous carbon nitride (Figure 1b-d) exhibited the opposite morphology with an enlarged dimension and abundant pores, which is greatly favorable for the dispersion and diffraction of the light toward the enhanced light absorption capacity. Meanwhile, TEM images (Figure 1e-g) displayed the mesoporous and lattice distance (Figure 1h) of $0.348 \mathrm{~nm}$.
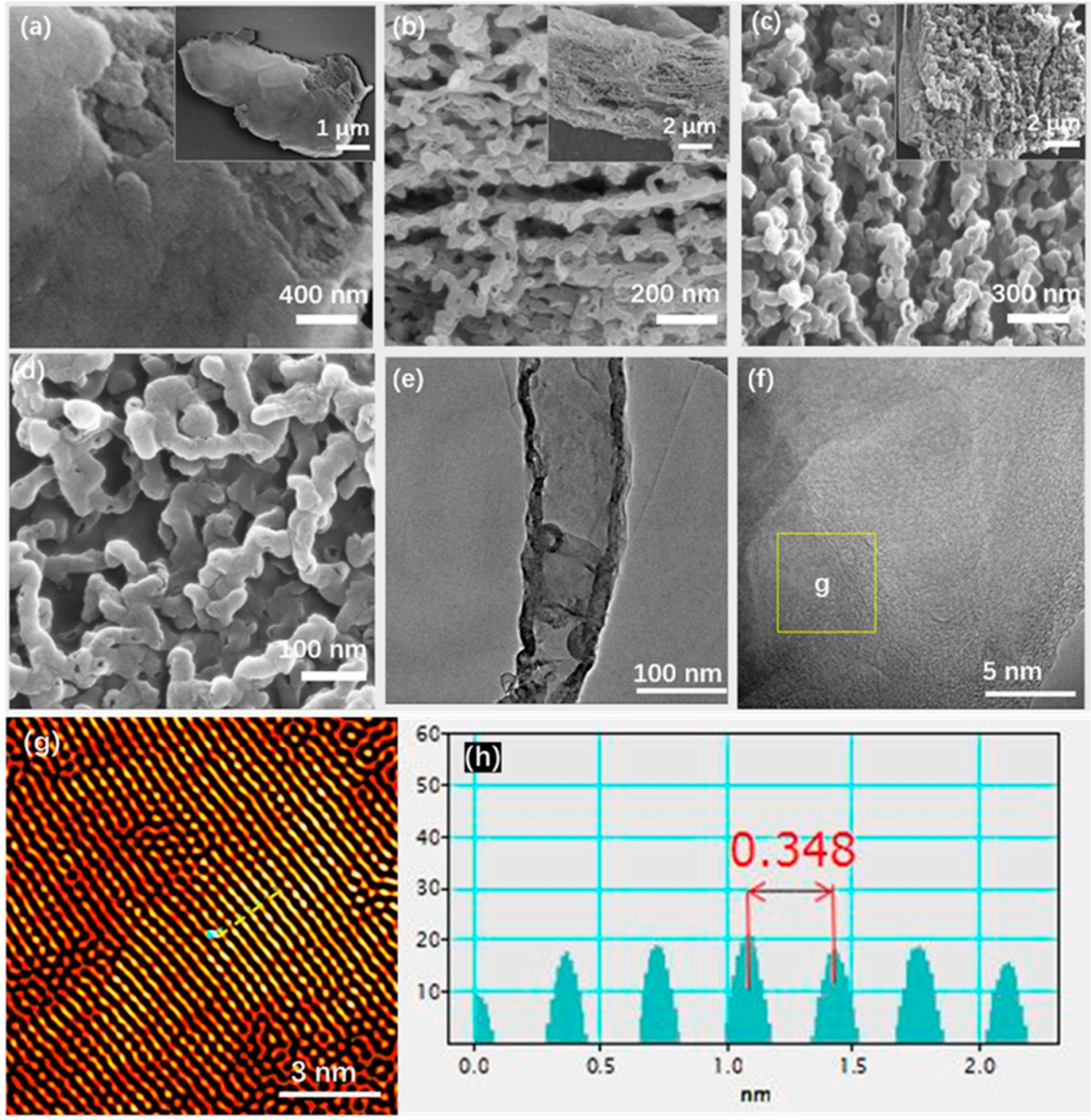

Figure 1. (a) SEM image of BCN, (b-d) SEM images of PPCN, (e-g) TEM images, and (h) lattice distance pattern of PPCN.

The structure can be exfoliated into hierarchical porous architecture and generated abundant pores using a suitable hybrid of alcohol and glycerol as the imbedding reagents which supporting abundant gas at the polycondensation process, leading to a hierarchical pancake-like porous architectural carbon nitride formation. $\mathrm{N}_{2}$ adsorption/desorption isotherms (Figure 2a) was performed to prove this unique structure. The calculated BET specific surface area of PPCN is $79.663 \mathrm{~m}^{2} \mathrm{~g}^{-1}$, which is seven-fold 
higher than that $\mathrm{BCN}\left(10.643 \mathrm{~m}^{2} \mathrm{~g}^{-1}\right)$. Meanwhile, the peak intensity centered at $37.2 \mathrm{~nm}$ in BJH pore distribution curves of PPCN sample (Figure $2 b$ ) also exhibited a larger value than $\mathrm{BCN}$ implying an abundant nanoporosity.
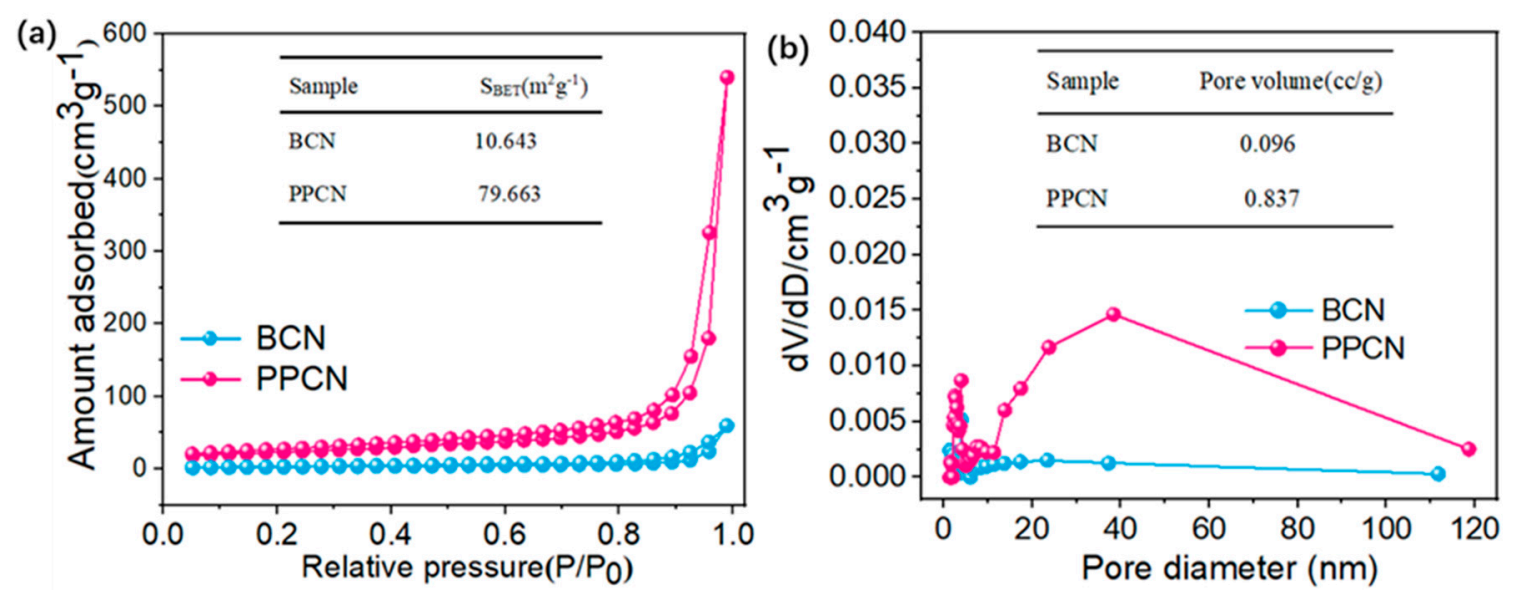

Figure 2. (a) $\mathrm{N}_{2}$ adsorption-desorption isotherm curves and (b) BJH pore size distribution curves of $\mathrm{BCN}$ and PPCN.

The XRD patterns of PPCN is shown in Figure 3a. Compared to the BCN, PPCN presented a broader and weaker diffraction peak located at $27.2^{\circ}(002)$, which is originated from the stacking reflection of interlayer toward a reduced dimension structure [53]. Meanwhile, the peak at $12.9^{\circ}$, ascribed to the repeats in the plane of tri-s-triazine unit could hardly been observed owing to the abundant pores in the interface. Fouriertransform infrared (FT-IR) spectroscopy (Figure 3b) demonstrates that the PPCN possessing a similar chemical structure with $B C N$. The $810 \mathrm{~cm}^{-1}$ peaks are characteristic signal of triazine unit, and the peaks ranges from 1200 to $1600 \mathrm{~cm}^{-1}$ is corresponding to the C-N heterocycles. In addition, the broad band peaks located at $3000-3600 \mathrm{~cm}^{-1}$ were contributed to- $\mathrm{NH}$ stretching vibrations [54]. It is notably that the terminal-NH absorption peak at $3000-3600 \mathrm{~cm}^{-1}$ of PPCN vibrate more strongly compared to that of $\mathrm{BCN}$, which can be attributed to the difference in the crystal structural between BCN and PPCN.

X-ray photoelectron spectroscopy (XPS) was further performed to investigate the composition and chemical states of BCN and PPCN. As can be seen in Figure 3c, the presence peaks of $C, N$, and $O$ are found both in the PPCN and BCN. It should be noted that the higher intensity of $\mathrm{O}$ 1s signal of PPCN is easy for the absorption of water and $\mathrm{CO}_{2}$ due to the hierarchical porous architecture structure. The corresponding high-resolution spectra of $\mathrm{C} 1 \mathrm{~s}, \mathrm{~N} 1 \mathrm{~s}, \mathrm{O} 1 \mathrm{~s}$ are shown in Figure $3 \mathrm{~d}-\mathrm{f}$, respectively. The $C 1$ s XPS spectrum revealed three peaks, which can be ascribed to the adventitious carbon species (284.4 eV) [55], C-NHX species on the edges of aromatic rings (286.03 eV) [56], and the sp²-hybridized C atom in $\mathrm{N}==\mathrm{C}(-\mathrm{N})_{2}(288.0 \mathrm{eV})$ [57], which is consistent with that of $\mathrm{BCN}$. The intensity of the $\mathrm{sp}^{2}$-bonded carbon of PPCN was increased compared to the $\mathrm{BCN}$ may be attributed to the loss of lattice nitrogen. The N 1s XPS signals can be deconvolved into three peaks at398.46, 399.75, and $400.93 \mathrm{eV}$, which originated from the $\mathrm{sp}^{2}$-hybridized $\mathrm{N}$ attached to $\mathrm{C}-\mathrm{N}=\mathrm{C}$ groups, bridging $\mathrm{N}$ in $\mathrm{N}-(\mathrm{C})_{3}$ groups, and the amine functional groups $(\mathrm{C}-\mathrm{N}-\mathrm{H})$, respectively [58,59]. Additionally, the $\mathrm{O} 1 \mathrm{~s}$ spectra can be divided into two peaks located at 532.68 and $530.71 \mathrm{eV}$, which belongs to the adsorbed water and $\mathrm{CO}_{2}$ [60]. 

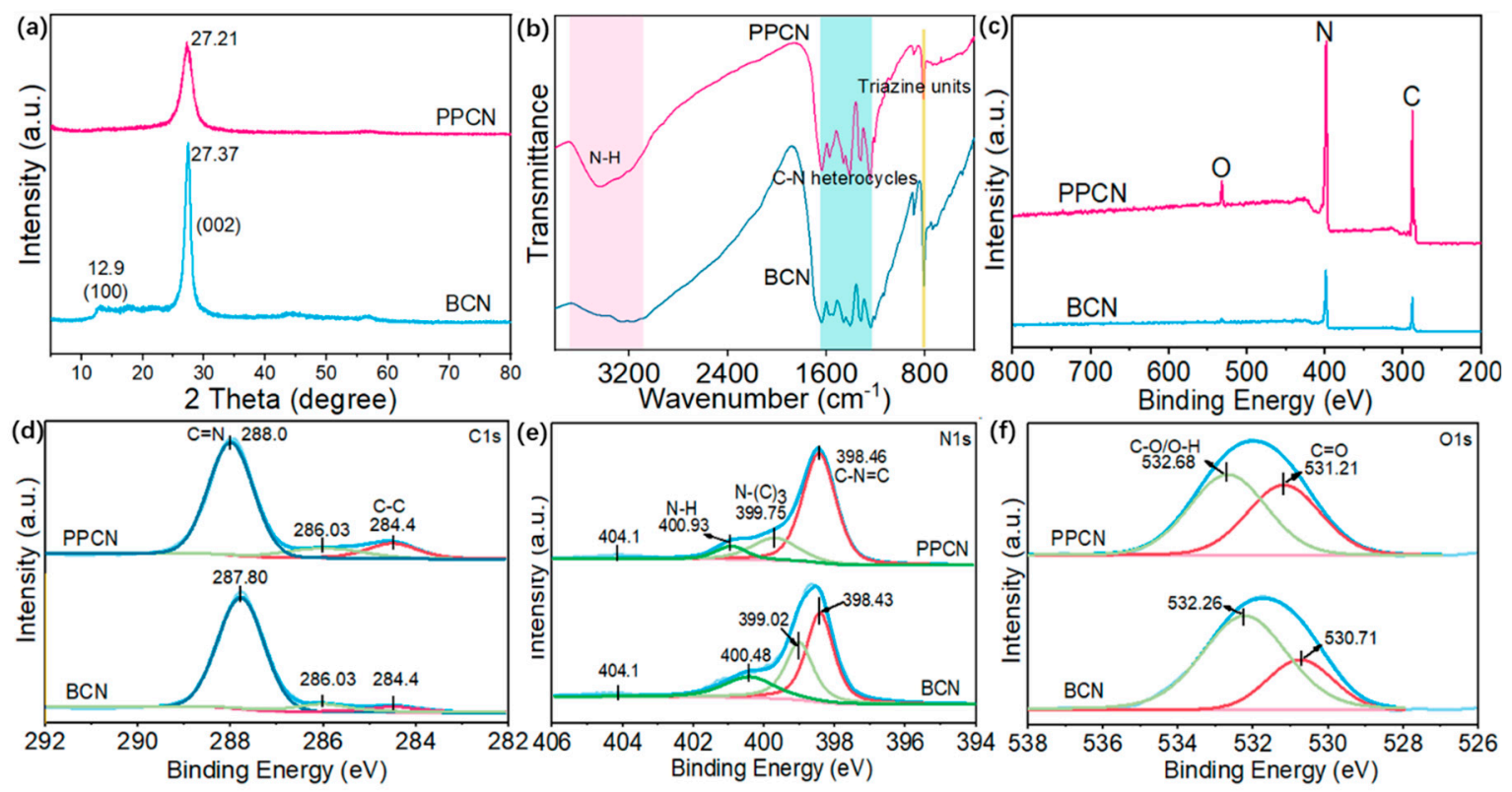

Figure 3. (a) XRD and (b) FT-IR spectra of BCN and PPCN, Survey and high-resolution XPS spectra of BCN and PPCN, (c) survey, (d) C 1s, (e) N 1s, and (f) O 1s of BCN and PPCN.

\subsection{Photoelectric Property}

UV-VIS diffuse reflectance (DRS) was used to assess the optical absorption properties of BCN and PPCN. Figure $4 \mathrm{a}$ indicates that BCN has an absorption edge at $460 \mathrm{~nm}$. Compared with BCN, the PPCN edge shows apparent blue shift, indicating the increase in band gap of semiconductors caused by the quantum confinement effect. The bandgaps for PPCN and BCN were 2.97 and $2.80 \mathrm{eV}$ according to the Kubelka-Munk function [61] (Figure 4b). Consequently, the enlarged bandgap of PPCN would endow the photo-induced electrons and holes with relatively stronger redox abilities toward photocatalytic reactions. The energy band structure of materials can be determined by the conduction band or valence band together with the band gap. In this article, we use the valence band to estimate the conduction band position [62]. The valence band (VB) in Figure 4c of BCN and PPCN was obtained by the XPS valence band spectra. From the band gap date in Figure $4 \mathrm{~b}$, the valence band potentials of PPCN and BCN were 1.98 and $2.30 \mathrm{eV}$ vs. NHE, respectively. Finally, the energy band structure was depicted in Figure 4d. Obviously, the more negative conduction band levels of PPCN would contribute to a more powerful $\mathrm{e}^{-}$reduction ability owing to the more negative $\mathrm{CB}$. 

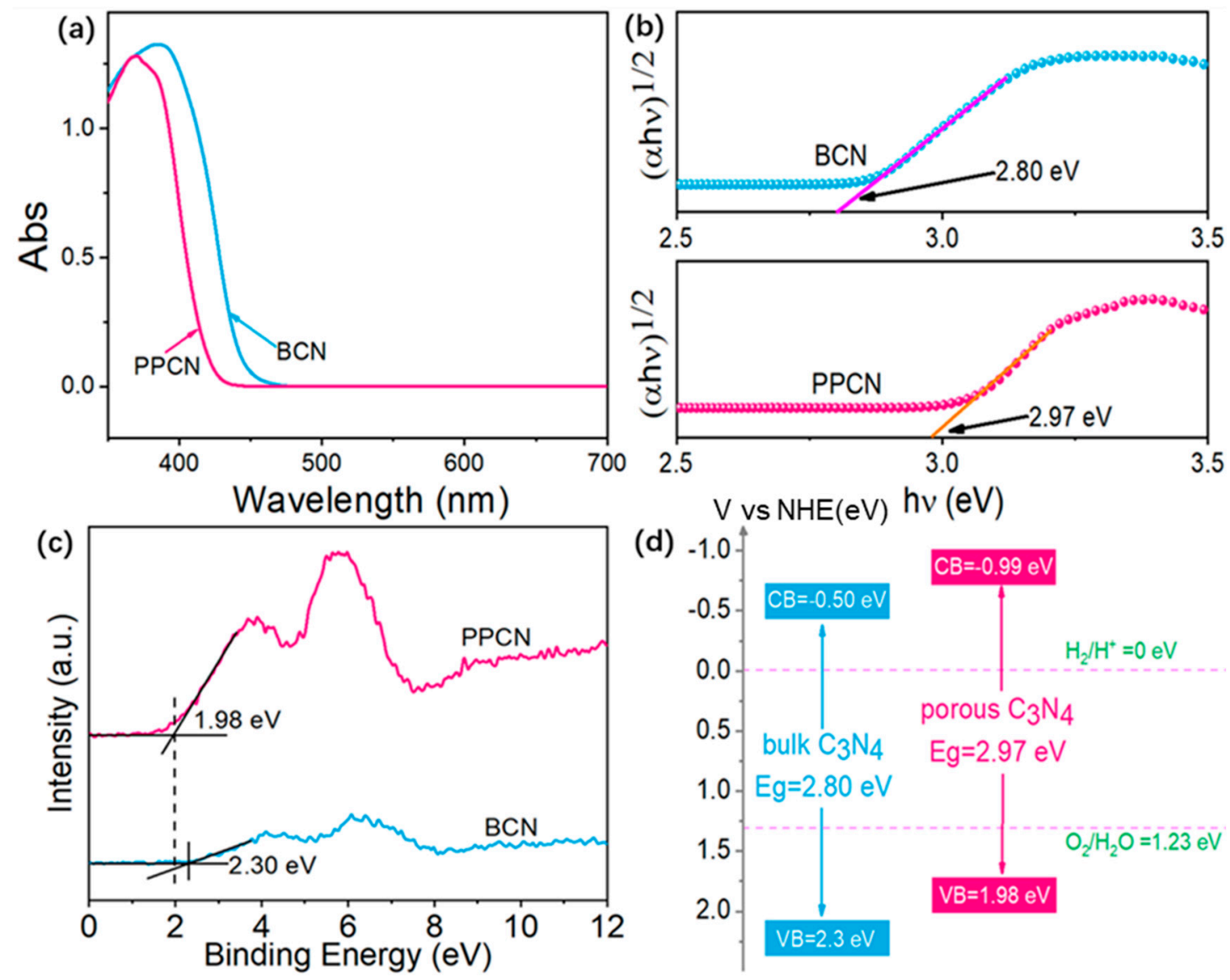

Figure 4. (a) UV-VIS DRS spectra and (b) Kubelka-Munk transformed function of BCN and PPCN, (c) valence band XPS spectra, (d) energy band structure of BCN and PPCN.

The photoluminescence tests were further performed with a $325 \mathrm{~nm}$ excitation wavelength to assess the separation efficiency of photo-induced electron-hole pairs. As shown in Figure 5a, PPCN presented a lower emission intensity compared with $\mathrm{BCN}$, which indicated of reduced recombination of photo-induced electron-hole pairs in PPCN. It is apparent from this image that the absorption peak of PPCN shifted to a lower value resulted from the quantum size confinement, which is consistent with the DRS.

The time-resolved PL decay spectra were also performed to evaluate the photo-physical characteristics of photogenerated charge carriers of BCN and PPCN. As shown in Figure 5b, the PPCN exhibited a slower exponential decay and fluorescence than that of $\mathrm{BCN}$. $\tau_{1}$ is originated from the free excitons recombination in semiconductor and $\tau_{2}$ is ascribed to the non-illuminated recombination of charge carriers in the surface defect states [63]. The short-lived and long-lived lifetime of charge carriers in PPCN (1.743 and $7.595 \mathrm{ns)}$ are both higher than that BCN (1.211 and 5.733 ns). Mostly, the calculated average lifetime in PPCN was $5.089 \mathrm{~ns}$ which substantially exceeds $3.696 \mathrm{~ns}$ in BCN. The prolonged carriers lifetime and larger percentage of long lifetime charge carriers in PPCN are undoubtedly favorable for promoting the probability of charge carries to involve in photocatalytic reactions. The photocurrent response can also prove this similar conclusion [64]. As depicted in Figure 5c, the PPCN exhibited increased photocurrent intensity than BCN during six light on-off recycles, demonstrating a more efficient separation and transfer of photo-induced electrons. Furthermore, PPCN exhibited a smaller charge transfer resistance (Figure 5d) than that of BCN. Therefore, the hierarchical pancake-like porous architectural structure of PPCN is benefit to the highly efficient separation and migration of photo-induced electron-hole pairs. 

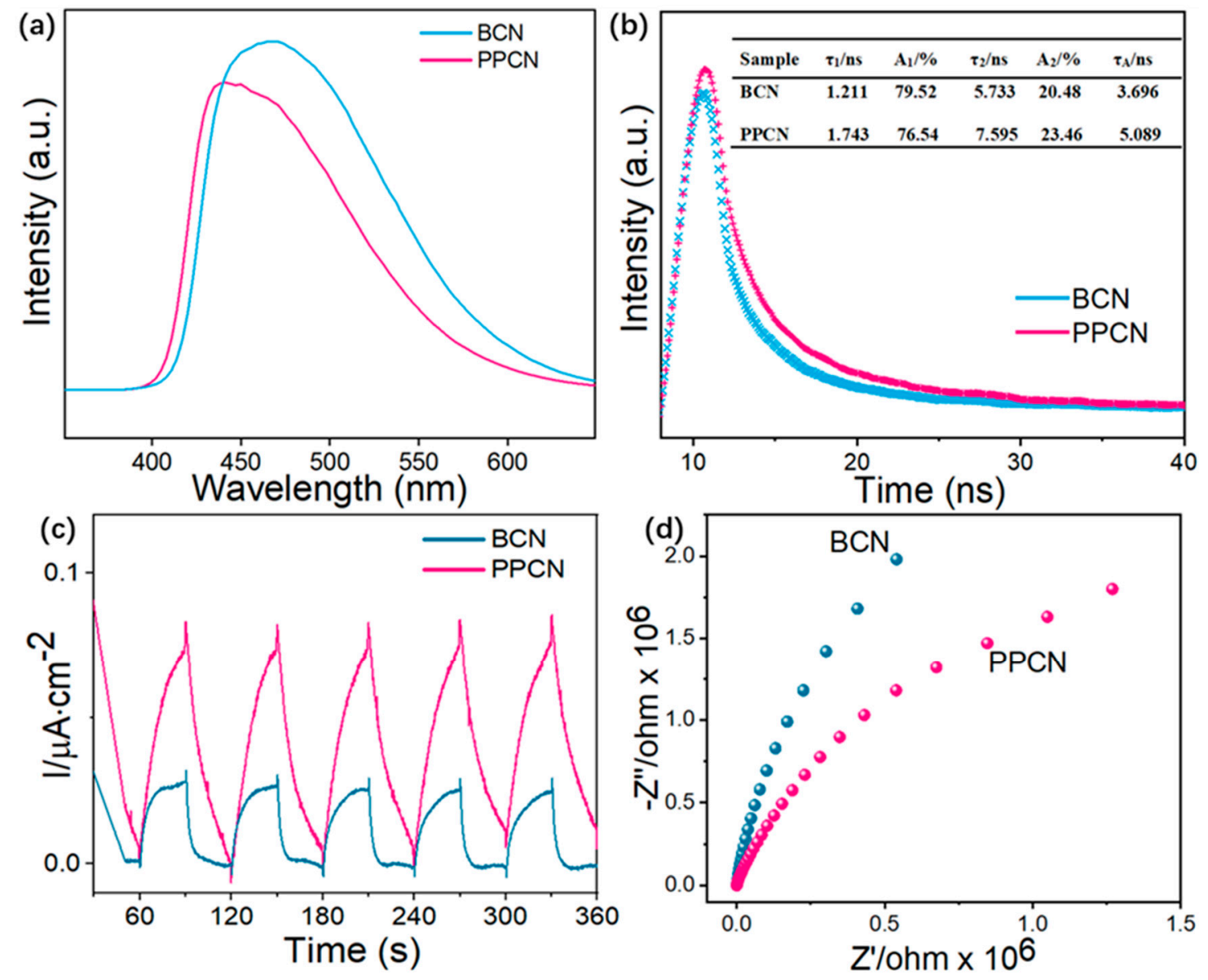

Figure 5. (a) Fluorescence emission spectra and (b) time-resolved fluorescence excited by incident light of $365 \mathrm{~nm}$ of BCN and PPCN, (c) photocurrent, and (d) EIS spectra of BCN and PPCN.

\subsection{Photocatalytic Performance}

Though photocatalyst based on carbon nitride without precious $\mathrm{Pt}$ is a trend in recent years [65-67], platinum plays a remarkable role in photocatalytic hydrogen production due to the low overpotential and the optimal Gibbs free energy for proton [68,69]. Figure 6a presented the HER of PPCN with $3 \% \mathrm{Pt}$ loading under visible light $(\lambda \geq 420 \mathrm{~nm})$ using $15 \mathrm{vol} \%$ TEOA as electron donor. As shown in Figure 6a, 3\%Pt@PPCN had an HER of $430 \mu \mathrm{mol} \mathrm{g}{ }^{-1} \mathrm{~h}^{-1}$, which was nine-fold higher than that of 3\%Pt@BCN (45 $\left.\mu \mathrm{mol} \mathrm{g}^{-1} \mathrm{~h}^{-1}\right)$. The apparent quantum yield (AQE) for the Pt@PPCN reached as high as 19\%at $420 \mathrm{~nm}$ (see the calculation in Supplementary Materials). Recycling production $\mathrm{H}_{2}$ evolution test of 3\%Pt@PPCN was further performed to assess the reusability of photocatalyst. As can be seen in Figure $6 b$, the PPCN maintained an excellent HER stability under visible light irradiation, demonstrating the excellent structure stability of PPCN.

Overall, a rational photocatalytic HER mechanism is illustrated in Scheme 2 based on the above results and discussions. Under visible light illumination, the electrons in the valence band (VB) of PPCN are activated to the conduction band (CB) and then are trapped by the Pt for proton reduction. The holes in the VB $(+1.98 \mathrm{eV})$ of PPCN oxidized the sacrificial regent TEOA and converted $\mathrm{H}_{2} \mathrm{O}$ into oxidation products (such as $\mathrm{H}_{2} \mathrm{O}_{2}$ ). The $\mathrm{CB}$ level of $\mathrm{PPCN}(-0.99 \mathrm{eV})$ is more negative than that of $\mathrm{BCN}(0.50 \mathrm{eV})$, which greatly boosted the reduction capacity of the PPCN. As a consequence, benefited from the 3D hierarchical pancake-like porous architecture, the utilization capacity of light absorption of PPCB would be forcefully enhanced by the scattering and diffraction in the pores and vertical plane, which significantly effective to boost the light-harvesting. More than that, the enlarged specific surface 
area offered more reactive sites and reduced the recombination rate of photogenerated $\mathrm{h}^{+}-\mathrm{e}^{-}$pairs, boosting a highly efficient photocatalytic $\mathrm{H}_{2}$ evolution reaction.
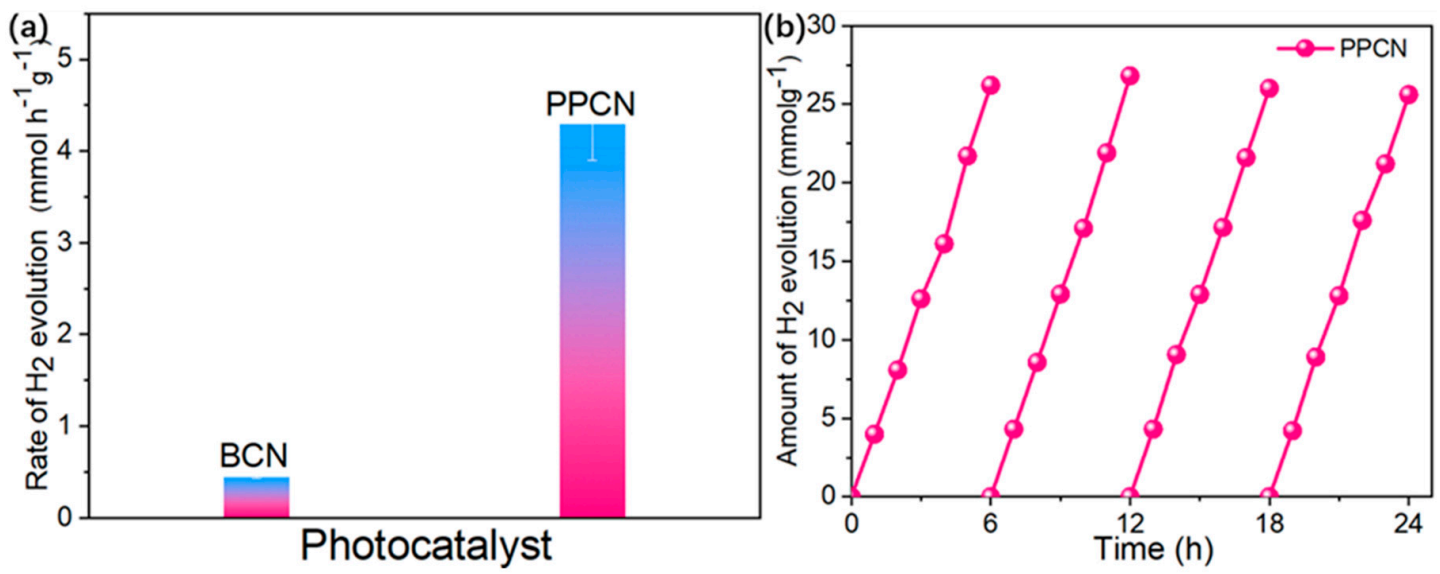

Figure 6. (a) $\mathrm{H}_{2}$ production of the $\mathrm{BCN}$ and PPCN with $3 \% \mathrm{Pt}$ loading, (b) cycling $\mathrm{H}_{2}$ production of 3 wt \% Pt@PPCN, Reaction conditions: $(\mathbf{a}, \mathbf{b})$ purified water photocatalytic $\mathrm{H}_{2}$ production with TEOA as sacrificial under visible light $(\lambda \geq 420 \mathrm{~nm})$, every $6 \mathrm{~h}$ as a period by recovering the catalyst and started with fresh purified water.

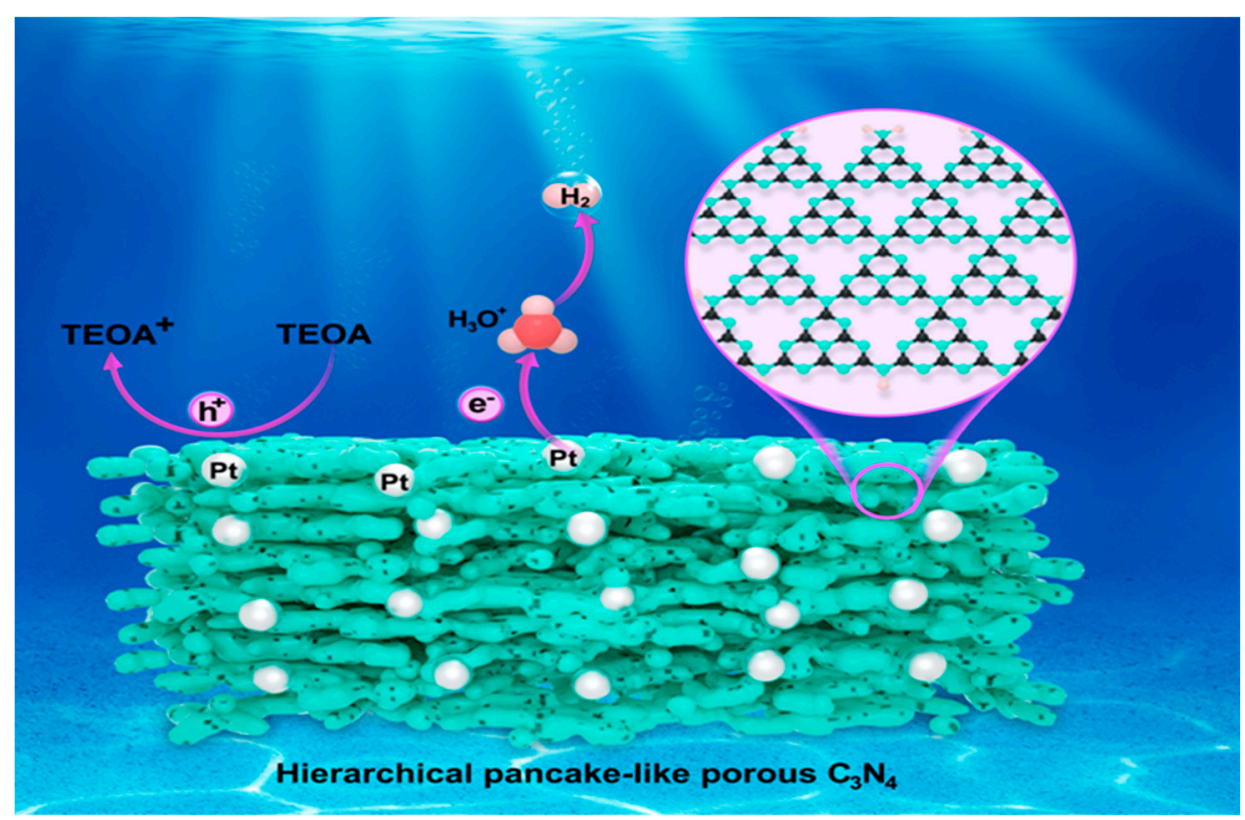

Scheme 2. Proposed photocatalysis charge transfer mechanism of Hierarchical pancake-like porous $\mathrm{C}_{3} \mathrm{~N}_{4}$ in TEOA solution.

\section{Experimental}

\subsection{Reagents}

Melamine was purchased from Tianjin Damao Chemical Regent Co., Ltd. (Tianjin, China). Phosphorous acid, glycerol, and ethanol were all supplied by Xilong Scientific Co., Ltd (Jiangsu, China). All reagents used in this study were at least of analytic grade without further purification. DI water was used in the whole experiment. 


\subsection{Synthesis of Bulk $C_{3} N_{4}$}

In the typical procedure, $10.0 \mathrm{~g}$ melamine powders were placed into a crucible sealed with a cover followed by calcinating at $550{ }^{\circ} \mathrm{C}$ for $4 \mathrm{~h}$ in a silica oxide tube furnace with a ramping rate of $2.5^{\circ} \mathrm{C} / \mathrm{min}$ under $\mathrm{N}_{2}$ flow $(99.999 \%, 50 \mathrm{~mL} / \mathrm{min})$. The as-obtained solid blocks were named bulk $\mathrm{C}_{3} \mathrm{~N}_{4}$.

\subsection{Synthesis of Precursor}

A total of $1.0 \mathrm{~g}$ melamine and $1.2 \mathrm{~g}$ phosphorous acid were added to $100 \mathrm{~mL}$ deionized water in a magnetic stirrer kept vigorous stirring for $1 \mathrm{~h}$ at $80^{\circ} \mathrm{C}$. Next, the solution was transferred into Teflon-lined stainless-steel autoclave at $180^{\circ} \mathrm{C}$ for $10 \mathrm{~h}$. The mixture was centrifuged, washed with deionized water for several times to obliterate the phosphorus species. Finally, the precursors were obtained after drying at $60^{\circ} \mathrm{C}$.

\subsection{Preparation of Hierarchical Pancake-Like Porous Carbon Nitride}

Typically, $0.6 \mathrm{~g}$ precursor was refluxed with a mixed aqueous solution of $5 \mathrm{mLglycerol}$ and $15 \mathrm{~mL}$ ethanol for $3 \mathrm{~h}$ in the temperature $90^{\circ} \mathrm{C}$. Then, the powders were washed by ethanol three times and dried at $60^{\circ} \mathrm{C}$. After that, the powders were transferred into a crucible tightly coated with a single layer aluminum foil paper. Finally, the crucible was placed into a muffler and heated to $500^{\circ} \mathrm{C}$ for $6 \mathrm{~h}$ with a ramping rate of $2{ }^{\circ} \mathrm{C} / \mathrm{min}$ to obtain the PPCN.

\subsection{Characterization}

X-ray diffraction (XRD, Shimadzu XRD-6100, Kyoto, Japan) was performed to identify the crystal phase and structural variation of the samples with a $\mathrm{Cu}-\mathrm{Ka}$ radiation at $40 \mathrm{kV}$ and $30 \mathrm{~mA}$. Scanning electron macroscopy (SEM, Zeiss Sigma, Jena, Germany) and transmission electron microscope (TEM, JEM-2010, JEOL, Tokyo, Janpan) images was recorded to study the morphologies of the samples. Fourier transform infrared (FT-IR) spectra (PerkinElmer Spectrum, Waltham, USA) were recorded to examine the surface functional groups of samples. X-ray photoelectron spectroscopy (XPS) was conducted on thermo ESCALAB 250XI (Axis Ultra DLD Kratos AXIS SUPRA; phi-5000 versaprobe). Nitrogen-adsorption-desorption isotherms (Quantachrome autosorb-IQ2, Quantachrome Instruments, Florida, USA) were performed to measure the specific surface area and pore volume of the samples in a Brunauer-Emmett-Teller (BET) method. UV-VIS diffusion reflectance spectra (DRS) of the samples were recorded on a PerkinElmer Lambda with $\mathrm{BaSO}_{4}$ as a reference. Photoluminescence (PL) spectra were recorded with an excitation wavelength of $325 \mathrm{~nm}$. The time-resolved fluorescence decay spectra were acquired on a Hamamatsu compact fluorescence lifetime spectrometer (C11367, Quantaurus-Tau, Hamamatsu, Japan) with $365 \mathrm{~nm}$ excitation wavelength and $470 \mathrm{~nm}$ emission wavelength.

\subsection{Electrochemical Analysis}

The photocurrent and electrochemical impedance spectroscopy (EIS) were investigated with a CHI660C electrochemical workstation equipped with standard three-electrodes in $0.5 \mathrm{M} \mathrm{Na}_{2} \mathrm{SO}_{4}$ aqueous solution. Among the electrodes, Photocatalyst was deposited on the Fluorine doped Tin Oxide (FTO) electrode and served as the photoanode. Pt wire as the counter electrode and saturated calomel electrode (SCE) as the reference electrode. The preparation approach of photoanode was presented as follows: $50 \mathrm{mg}$ catalyst was dispersed in $100 \mu \mathrm{L}$ ethanol to obtain a slurry. Next, the slurry was carefully coated onto a $7 \mathrm{~mm} \times 14 \mathrm{~mm}$ FTO conductive glass and dried in room temperature. A $500 \mathrm{~W}$ Xe lamp quipped with a $420 \mathrm{~nm}$ cut-off filter was used as the light irradiation source. The EIS spectrum was recorded using the PPCN as the working electrode at a potential of $0.24 \mathrm{~V}$ versus SCE with the frequency ranging from $1 \mathrm{MHz}$ to $0.01 \mathrm{~Hz}$. 


\subsection{Photocatalytic Hydrogen Evolution}

Photocatalytic hydrogen production performance was performed via a sealed reactor and a recirculated cooling water system. Typically, $25 \mathrm{mg}$ of photocatalyst powder was dissolved in $80 \mathrm{~mL}$ aqueous solution ( $68 \mathrm{~mL} 3 \mathrm{wt} \% \mathrm{H}_{2} \mathrm{PtCl}_{6}$ solution and $12 \mathrm{~mL}$ triethanolamine). After that, the reactor was degassed and illuminated $2 \mathrm{~h}$ under a full arc light $120 \mathrm{~mW} \cdot \mathrm{cm}^{-2}(\lambda>300 \mathrm{~nm})$ with a $420 \mathrm{~nm}$ wavelength cut off. Finally, the generated hydrogen was monitored by GC.

\section{Conclusions}

In summary, a 3D hierarchical pancake-like porous carbon nitride with remarkable photocatalytic $\mathrm{H}_{2}$ production efficiency was synthesized by a facile bottom-up strategy. $3 \mathrm{wt} \% @ \mathrm{Pt} / \mathrm{PPCN}$ showed $430 \mu \mathrm{mol} \mathrm{g}{ }^{-1} \mathrm{~h}^{-1}$ for photocatalytic $\mathrm{H}_{2}$ production under visible light $(\lambda \geq 420 \mathrm{~nm})$, which was nine times higher than that of $3 \mathrm{wt} \% @ \mathrm{Pt} / \mathrm{BCN}\left(45 \mu \mathrm{mol} \mathrm{g}^{-1} \mathrm{~h}^{-1}\right)$. The enlarged specific surface area, prolonged charge carriers lifetime, boosted light-harvesting and utilization capacity, and improved charge separation and transfer efficiency are all contributed to the optimized photocatalytic capacity. In addition, this research provides a simple and environmental-friendly approach to design highly-efficient polymeric carbon nitride catalysts for potential applications in solar energy-driven photocatalytic water splitting.

Supplementary Materials: The following are available online at http://www.mdpi.com/2073-4344/10/1/77/s1.

Author Contributions: Conceptualization, X.Q., L.Q. and S.D.; validation, X.Q., L.Q. and S.D.; formal analysis, X.Q.; investigation, X.Q.; resources, X.Q.; data curation, X.Q., M.M. and Y.H.; writing-original draft preparation, X.Q.; writing-review and editing, X.Q.; visualization, X.Q.; supervision, L.Q. and S.D.; project administration, L.Q. and S.D.; funding acquisition, L.Q. and S.D. All authors have read and agreed to the published version of the manuscript.

Funding: The authors gratefully acknowledge the support from the financial support of National Natural Science Foundation of China (no.41763020), the Natural Science Foundation of Jiangxi Province (No.20171BAB206008), the Foundation of Jiangxi Educational Commission (no. GJJ180596, GJJ180603), and the Doctoral Scientific Research Starting Foundation of Jiangxi Science and Technology Normal University (no. 2017BSQD003).

Conflicts of Interest: The authors declare no conflict of interest.

\section{References}

1. Asif, M.; Muneer, T. Energy supply, its demand and security issues for developed and emerging economies. Renew. Sustain. Energy Rev. 2007, 11, 1388-1413. [CrossRef]

2. Wang, X.; Blechert, S.; Antonietti, M. Polymeric Graphitic Carbon Nitride for Heterogeneous Photocatalysis. ACS Catal. 2012, 2, 1596-1606. [CrossRef]

3. Zhang, C.; Zeng, G.; Huang, D.; Lai, C.; Chen, M.; Cheng, M.; Tang, W.; Tang, L.; Dong, H.; Huang, B.; et al. Biochar for environmental management: Mitigating greenhouse gas emissions, contaminant treatment, and potential negative impacts. Chem. Eng. J. 2019, 373, 902-922. [CrossRef]

4. Mahmood, J.; Li, F.; Jung, S.M.; Okyay, M.S.; Ahmad, I.; Kim, S.J.; Park, N.; Jeong, H.Y.; Baek, J.B. An efficient and $\mathrm{pH}$-universal ruthenium-based catalyst for the hydrogen evolution reaction. Nat. Nanotechnol. 2017, 12, 441-446. [CrossRef]

5. Liu, J.; Liu, Y.; Liu, N.; Han, Y.; Zhang, X.; Huang, H.; Lifshitz, Y.; Lee, S.-T.; Zhong, J.; Kang, Z. Metal-free efficient photocatalyst for stable visible water splitting via a two-electron pathway. Science 2015, 347, 970-974. [CrossRef] [PubMed]

6. Zhang, C.; Lai, C.; Zeng, G.; Huang, D.; Yang, C.; Wang, Y.; Zhou, Y.; Cheng, M. Efficacy of carbonaceous nanocomposites for sorbing ionizable antibiotic sulfamethazine from aqueous solution. Water Res. 2016, 95, 103-112. [CrossRef]

7. Fujishima, A.; Honda, K. Electrochemical Photolysis of Water at a Semiconductor Electrode. Nature 1972, 238, 37-38. [CrossRef]

8. Xiong, B.; Chen, L.; Shi, J. Anion-Containing Noble-Metal-Free Bifunctional Electrocatalysts for Overall Water Splitting. ACS Catal. 2018, 8, 3688-3707. [CrossRef] 
9. Wu, J.; Li, N.; Fang, H.-B.; Li, X.; Zheng, Y.-Z.; Tao, X. Nitrogen vacancies modified graphitic carbon nitride: Scalable and one-step fabrication with efficient visible-light-driven hydrogen evolution. Chem. Eng. J. 2019, 358, 20-29. [CrossRef]

10. Rahman, M.Z.; Davey, K.; Qiao, S.Z. Carbon, nitrogen and phosphorus containing metal-free photocatalysts for hydrogen production: Progress and challenges. J. Mater. Chem. A 2018, 6, 1305-1322. [CrossRef]

11. Rahman, M.Z.; Davey, K.; Mullins, C.B. Tuning the intrinsic properties of carbon nitride for high Quantum yield photocatalytic hydrogen production. Adv. Sci. 2018, 5, 1800820. [CrossRef] [PubMed]

12. Rahman, M.Z.; Mullins, C.B. Understanding charge transport in carbon nitride for enhanced photocatalytic solar fuel production. Acc. Chem. Res. 2019, 52, 248-257. [CrossRef] [PubMed]

13. Yang, J.; Wang, D.; Han, H.; Li, C. Roles of cocatalysts in photocatalysis and photoelectrocatalysis. Acc. Chem. Res. 2013, 46, 1900-1909. [CrossRef] [PubMed]

14. Walter, M.G.; Warren, E.L.; McKone, J.R.; Boettcher, S.W.; Mi, Q.; Santori, E.A.; Lewis, N.S. Solar water splitting cells. Chem. Rev. 2010, 110, 6446-6473. [CrossRef] [PubMed]

15. Tu, W.; Zhou, Y.; Zou, Z. Versatile graphene-promoting photocatalytic performance of semiconductors: Basic principles, synthesis, solar energy conversion, and environmental applications. Adv. Funct. Mater. 2013, 23, 4996-5008. [CrossRef]

16. Kapilashrami, M.; Zhang, Y.; Liu, Y.S.; Hagfeldt, A.; Guo, J. Probing the optical property and electronic structure of $\mathrm{TiO}_{2}$ nanomaterials for renewable energy applications. Chem. Rev. 2014, 114, 9662-9707. [CrossRef]

17. Li, X.; Wang, T.; Duan, P.; Baldini, M.; Huang, H.T.; Chen, B.; Juhl, S.J.; Koeplinger, D.; Crespi, V.H.; Schmidt-Rohr, K.; et al. Carbon nitride nanothread crystals derived from pyridine. J. Am. Chem. Soc. 2018, 140, 4969-4972. [CrossRef]

18. Li, J.; Zhang, Z.; Cui, W.; Wang, H.; Cen, W.; Johnson, G.; Jiang, G.; Zhang, S.; Dong, F. The spatially oriented charge flow and photocatalysis mechanism on internal van der waals heterostructures enhanced g- $\mathrm{C}_{3} \mathrm{~N}_{4}$. ACS Catal. 2018, 8, 8376-8385. [CrossRef]

19. Huang, D.; Luo, H.; Zhang, C.; Zeng, G.; Lai, C.; Cheng, M.; Wang, R.; Deng, R.; Xue, W.; Gong, X.; et al. Nonnegligible role of biomass types and its compositions on the formation of persistent free radicals in biochar: Insight into the influences on Fenton-like process. Chem. Eng. J. 2019, 361, 353-363. [CrossRef]

20. Han, C.; Meng, P.; Waclawik, E.R.; Zhang, C.; Li, X.H.; Yang, H.; Antonietti, M.; Xu, J. Palladium/graphitic carbon nitride $\left(\mathrm{g}-\mathrm{C}_{3} \mathrm{~N}_{4}\right)$ stabilized emulsion microreactor as a store for hydrogen from ammonia borane for use in alkene hydrogenation. Angew. Chem. Int. Ed. 2018, 57, 14857-14861. [CrossRef]

21. Cao, S.; Yu, J. g-C3N4-Based Photocatalysts for hydrogen generation. J. Phys. Chem. Lett. 2014, 5, $2101-2107$. [CrossRef] [PubMed]

22. Cao, S.; Li, H.; Tong, T.; Chen, H.-C.; Yu, A.; Yu, J.; Chen, H.M. Single-atom engineering of directional charge transfer channels and active sites for photocatalytic hydrogen evolution. Adv. Funct. Mater. 2018, 28. [CrossRef]

23. Zhang, J.; Chen, X.; Takanabe, K.; Maeda, K.; Domen, K.; Epping, J.D.; Fu, X.; Antonietti, M.; Wang, X. Synthesis of a carbon nitride structure for visible-light catalysis by copolymerization. Angew. Chem. Int. Ed. 2010, 49, 441-444. [CrossRef] [PubMed]

24. Xiao, Y.; Tian, G.; Li, W.; Xie, Y.; Jiang, B.; Tian, C.; Zhao, D.; Fu, H. Molecule self-assembly synthesis of porous few-layer carbon nitride for highly efficient photoredox catalysis. J. Am. Chem. Soc. 2019, 141, 2508-2515. [CrossRef] [PubMed]

25. Wen, X.; Sun, N.; Tan, Y.; Wang, W.; Yan, C.; Wang, H. One-step synthesis of petals-like graphitic carbon nitride nanosheets with triazole defects for highly improved photocatalytic hydrogen production. Int. J. Hydrogen Energy 2019, 44, 2675-2684. [CrossRef]

26. Shu, Z.; Wang, Y.; Wang, W.; Zhou, J.; Li, T.; Liu, X.; Tan, Y.; Zhao, Z. A green one-pot approach for mesoporous g- $\mathrm{C}_{3} \mathrm{~N}_{4}$ nanosheets with in situ sodium doping for enhanced photocatalytic hydrogen evolution. Int. J. Hydrogen Energy 2019, 44, 748-756. [CrossRef]

27. Liu, Q.; Shen, J.; Yu, X.; Yang, X.; Liu, W.; Yang, J.; Tang, H.; Xu, H.; Li, H.; Li, Y.; et al. Unveiling the origin of boosted photocatalytic hydrogen evolution in simultaneously $(\mathrm{S}, \mathrm{P}, \mathrm{O})$-codoped and exfoliated ultrathin g- $\mathrm{C}_{3} \mathrm{~N}_{4}$ nanosheets. Appl. Catal. B Environ. 2019, 248, 84-94. [CrossRef]

28. Kessler, F.K.; Zheng, Y.; Schwarz, D.; Merschjann, C.; Schnick, W.; Wang, X.; Bojdys, M.J. Functional carbon nitride materials-design strategies for electrochemical devices. Nat. Rev. Mater. 2017, 2, 17030. [CrossRef] 
29. Wang, Y.; Zhang, J.; Wang, X.; Antonietti, M.; Li, H. Boron- and fluorine-containing mesoporous carbon nitride polymers: Metal-free catalysts for cyclohexane oxidation. Angew. Chem. Int. Ed. 2010, 49, 3356-3359. [CrossRef]

30. Cao, S.; Fan, B.; Feng, Y.; Chen, H.; Jiang, F.; Wang, X. Sulfur-doped $g-\mathrm{C}_{3} \mathrm{~N}_{4}$ nanosheets with carbon vacancies: General synthesis and improved activity for simulated solar-light photocatalytic nitrogen fixation. Chem. Eng. J. 2018, 353, 147-156. [CrossRef]

31. Yang, C.; Wang, Z.; Lin, T.; Yin, H.; Lu, X.; Wan, D.; Xu, T.; Zheng, C.; Lin, J.; Huang, F.; et al. Core-shell nanostructured black rutile titania as excellent catalyst for hydrogen production enhanced by sulfur doping. J. Am. Chem. Soc. 2013, 135, 17831-17838. [CrossRef] [PubMed]

32. Asahi, R.; Morikawa, T.; Ohwaki, T.; Aoki, K.; Taga, Y. Visible-light photocatalysis in nitrogen-doped titanium oxides. Science 2001, 293, 269-271. [CrossRef] [PubMed]

33. Zhou, G.; Shan, Y.; Hu, Y.; Xu, X.; Long, L.; Zhang, J.; Dai, J.; Guo, J.; Shen, J.; Li, S.; et al. Half-metallic carbon nitride nanosheets with micro grid mode resonance structure for efficient photocatalytic hydrogen evolution. Nat. Commun. 2018, 9, 3366. [CrossRef] [PubMed]

34. Tong, Z.; Yang, D.; Li, Z.; Nan, Y.; Ding, F.; Shen, Y.; Jiang, Z. Thylakoid-inspired multishell g- $\mathrm{C}_{3} \mathrm{~N}_{4}$ nanocapsules with enhanced visible-Light harvesting and electron transfer properties for high-Efficiency photocatalysis. ACS Nano 2017, 11, 1103-1112. [CrossRef] [PubMed]

35. Youngblood, W.J.; Lee, S.-H.A.; Kobayashi, Y.; Hernandez-Pagan, E.A.; Hoertz, P.G.; Moore, T.A.; Moore, A.L.; Gust, D.; Mallouk, T.E. Photoassisted overall water splitting in a visible light-absorbing dye-sensitized photoelectrochemical Cell. J. Am. Chem. Soc. 2009, 131, 926-927. [CrossRef]

36. Xue, Y.; Lei, Y.; Liu, X.; Li, Y.; Deng, W.; Wang, F.; Min, S. Highly active dye-sensitized photocatalytic $\mathrm{H}_{2}$ evolution catalyzed by a single-atom Pt cocatalyst anchored onto g- $\mathrm{C}_{3} \mathrm{~N}_{4}$ nanosheets under long-wavelength visible light irradiation. New J. Chem. 2018, 42, 14083-14086. [CrossRef]

37. Wang, P.; Guan, Z.; Li, Q.; Yang, J. Efficient visible-light-driven photocatalytic hydrogen production from water by using Eosin Y-sensitized novel g- $\mathrm{C}_{3} \mathrm{~N}_{4} / \mathrm{Pt} / \mathrm{GO}$ composites. J. Mater. Sci. 2017, 53, 774-786. [CrossRef]

38. Zhu, M.; Kim, S.; Mao, L.; Fujitsuka, M.; Zhang, J.; Wang, X.; Majima, T. Metal-Free Photocatalyst for $\mathrm{H}_{2}$ evolution in visible to near-infrared region: Black phosphorus/graphitic carbon nitride. J. Am. Chem. Soc. 2017, 139, 13234-13242. [CrossRef]

39. Sun, J.; Guo, Y.; Wang, Y.; Cao, D.; Tian, S.; Xiao, K.; Mao, R.; Zhao, X. $\mathrm{H}_{2} \mathrm{O}_{2}$ assisted photoelectrocatalytic degradation of diclofenac sodium at $\mathrm{g}_{-} \mathrm{C}_{3} \mathrm{~N}_{4} / \mathrm{BiVO}_{4}$ photoanode under visible light irradiation. Chem. Eng. J. 2018, 332, 312-320. [CrossRef]

40. Liu, Y.; Yang, S.; Yin, S.-N.; Feng, L.; Zang, Y.; Xue, H. In situ construction of fibrous AgNPs/g- $\mathrm{C}_{3} \mathrm{~N}_{4}$ aerogel toward light-driven COx-free methanol dehydrogenation at room temperature. Chem. Eng. J. 2018, 334, 2401-2407. [CrossRef]

41. Bafaqeer, A.; Tahir, M.; Amin, N.A.S. Well-designed $\mathrm{ZnV}_{2} \mathrm{O}_{6} / g-\mathrm{C}_{3} \mathrm{~N}_{4} 2 \mathrm{D} / 2 \mathrm{D}$ nanosheets heterojunction with faster charges separation via $\mathrm{pCN}$ as mediator towards enhanced photocatalytic reduction of $\mathrm{CO}_{2}$ to fuels. Appl. Catal. B Environ. 2019, 242, 312-326. [CrossRef]

42. Tan, C.; Cao, X.; Wu, X.J.; He, Q.; Yang, J.; Zhang, X.; Chen, J.; Zhao, W.; Han, S.; Nam, G.H.; et al. Recent Advances in Ultrathin Two-Dimensional Nanomaterials. Chem. Rev. 2017, 117, 6225-6331. [CrossRef]

43. Rahman, M.Z.; Kwong, C.W.; Davey, K.; Qiao, S.Z. 2D phosphorene as a water splitting photocatalyst: Fundamentals to applications. Energy Environ. Sci. 2016, 9, 709-728. [CrossRef]

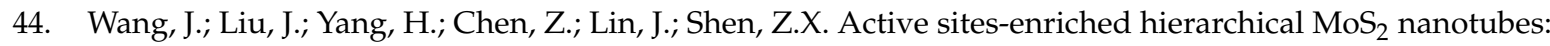
Highly active and stable architecture for boosting hydrogen evolution and lithium storage. J. Mater. Chem. A 2016, 4, 7565-7572. [CrossRef]

45. Tian, N.; Zhang, Y.; Li, X.; Xiao, K.; Du, X.; Dong, F.; Waterhouse, G.I.N.; Zhang, T.; Huang, H. Precursor-reforming protocol to $3 \mathrm{D}$ mesoporous $\mathrm{g}-\mathrm{C}_{3} \mathrm{~N}_{4}$ established by ultrathin self-doped nanosheets for superior hydrogen evolution. Nano Energy 2017, 38, 72-81. [CrossRef]

46. Han, Q.; Wang, B.; Gao, J.; Cheng, Z.; Zhao, Y.; Zhang, Z.; Qu, L. Atomically thin mesoporous nanomesh of graphitic $\mathrm{C}_{3} \mathrm{~N}_{4}$ for high-efficiency photocatalytic hydrogen evolution. ACS Nano 2016, 10, 2745-2751. [CrossRef]

47. Jiang, Y.; Sun, Z.; Tang, C.; Zhou, Y.; Zeng, L.; Huang, L. Enhancement of photocatalytic hydrogen evolution activity of porous oxygen doped $g-\mathrm{C}_{3} \mathrm{~N}_{4}$ with nitrogen defects induced by changing electron transition. Appl. Catal. B Environ. 2019, 240, 30-38. [CrossRef] 
48. Shalom, M.; Inal, S.; Fettkenhauer, C.; Neher, D.; Antonietti, M. Improving carbon nitride photocatalysis by supramolecular preorganization of monomers. J. Am. Chem. Soc. 2013, 135, 7118-7121. [CrossRef]

49. Gu, Q.; Gao, Z.; Xue, C. Self-sensitized carbon nitride microspheres for long-lasting visible-light-driven hydrogen generation. Small 2016, 12, 3543-3549. [CrossRef]

50. Kang, Y.; Yang, Y.; Yin, L.C.; Kang, X.; Liu, G.; Cheng, H.M. An amorphous carbon nitride photocatalyst with greatly extended visible-light-responsive range for photocatalytic hydrogen generation. Adv. Mater. 2015, 27, 4572-4577. [CrossRef]

51. Rahman, M.Z.; Tapping, P.C.; Kee, T.W.; Smernik, R.; Spooner, N.; Moffatt, J.; Tang, Y.; Davey, K.; Qiao, S.-Z. A benchmark quantum yield for water photoreduction on amorphous carbon nitride. Adv. Funct. Mater. 2017, 27, 1702384. [CrossRef]

52. Guo, S.; Deng, Z.; Li, M.; Jiang, B.; Tian, C.; Pan, Q.; Fu, H. Phosphorus-doped carbon nitride tubes with a layered micro-nanostructure for enhanced visible-light photocatalytic hydrogen evolution. Angew. Chem. Int. Ed. 2016, 55, 1830-1834. [CrossRef]

53. Wang, X.; Maeda, K.; Thomas, A.; Takanabe, K.; Xin, G.; Carlsson, J.M.; Domen, K.; Antonietti, M. A metal-free polymeric photocatalyst for hydrogen production from water under visible light. Nat. Mater. 2009, 8, 76-80. [CrossRef]

54. Niu, P.; Zhang, L.; Liu, G.; Cheng, H.-M. Graphene-like carbon nitride nanosheets for improved photocatalytic activities. Adv. Funct. Mater. 2012, 22, 4763-4770. [CrossRef]

55. Shinde, S.S.; Lee, C.H.; Yu, J.Y.; Kim, D.H.; Lee, S.U.; Lee, J.H. Hierarchically designed 3D holey $\mathrm{C}_{2} \mathrm{~N}$ aerogels as bifunctional oxygen electrodes for flexible and rechargeable Zn-Air batteries. ACS Nano 2018, 12, 596-608. [CrossRef]

56. Wulan, B.-R.; Yi, S.-S.; Li, S.-J.; Duan, Y.-X.; Yan, J.-M.; Jiang, Q. Amorphous nickel pyrophosphate modified graphitic carbon nitride: An efficient photocatalyst for hydrogen generation from water splitting. Appl. Catal. B Environ. 2018, 231, 43-50. [CrossRef]

57. Shinde, S.S.; Sami, A.; Lee, J.-H. Sulfur mediated graphitic carbon nitride/S-Se-graphene as a metal-free hybrid photocatalyst for pollutant degradation and water splitting. Carbon 2016, 96, 929-936. [CrossRef]

58. Shen, R.; Xie, J.; Zhang, H.; Zhang, A.; Chen, X.; Li, X. Enhanced solar fuel $\mathrm{H}_{2}$ generation over g- $\mathrm{C}_{3} \mathrm{~N}_{4}$ nanosheet photocatalysts by the synergetic effect of noble metal-free $\mathrm{Co}_{2} \mathrm{P}$ cocatalyst and the environmental phosphorylation strategy. ACS Sustain. Chem. Eng. 2017, 6, 816-826. [CrossRef]

59. Shinde, S.S.; Sami, A.; Lee, J.-H. Nitrogen- and phosphorus-doped nanoporous graphene/graphitic carbon nitride hybrids as efficient electrocatalysts for hydrogen evolution. ChemCatChem 2015, 7, 3873-3880. [CrossRef]

60. Tang, H.; Wang, R.; Zhao, C.; Chen, Z.; Yang, X.; Bukhvalov, D.; Lin, Z.; Liu, Q. Oxamide-modified g- $\mathrm{C}_{3} \mathrm{~N}_{4}$ nanostructures: Tailoring surface topography for high-performance visible light photocatalysis. Chem. Eng. J. 2019, 374, 1064-1075. [CrossRef]

61. Marci, G.; Garcia-Lopez, E.I.; Pomilla, F.R.; Palmisano, L.; Zaffora, A.; Santamaria, M.; Krivtsov, I.; Ilkaeva, M.; Barbierikova, Z.; Brezova, V. Photoelectrochemical and EPR features of polymeric $\mathrm{C}_{3} \mathrm{~N}_{4}$ and O-modified $\mathrm{C}_{3} \mathrm{~N}_{4}$ employed for selective photocatalytic oxidation of alcohols to aldehydes. Catal. Today 2019, 328, 21-28. [CrossRef]

62. Rahman, M.; Davey, K.; Qiao, S.Z. Counteracting blueshift optical absorption and maximizing photon harvest in carbon nitride nanosheet photocatalyst. Small 2017, 13, 1700376. [CrossRef]

63. Zeng, Y.; Liu, X.; Liu, C.; Wang, L.; Xia, Y.; Zhang, S.; Luo, S.; Pei, Y. Scalable one-step production of porous oxygen-doped $\mathrm{g}-\mathrm{C}_{3} \mathrm{~N}_{4}$ nanorods with effective electron separation for excellent visible-light photocatalytic activity. Appl. Catal. B Environ. 2018, 224,1-9. [CrossRef]

64. Yang, L.; Huang, J.; Shi, L.; Cao, L.; Yu, Q.; Jie, Y.; Fei, J.; Ouyang, H.; Ye, J. A surface modification resultant thermally oxidized porous $\mathrm{g}^{-} \mathrm{C}_{3} \mathrm{~N}_{4}$ with enhanced photocatalytic hydrogen production. Appl. Catal. B Environ. 2017, 204, 335-345. [CrossRef]

65. Rahman, M.; Davey, K. Enabling Pt-free photocatalytic hydrogen evolution on polymeric melon: Role of amorphization for overcoming the limiting factors. Phys. Rev. Mater. 2018, 2, 125402. [CrossRef]

66. Rahman, M.Z.; Tang, Y.; Kwong, P. Reduced recombination and low-resistive transport of electrons for photo-redox reactions in metal-free hybrid photocatalyst. Appl. Phys. Lett. 2018, 112, 253902. [CrossRef] 
67. Rahman, M.Z.; Moffatt, J.; Spooner, N. Topological carbon nitride: Localized photon absorption and delocalized charge carrier separation at intertwined photocatalyst interfaces. Mater. Horiz. 2018, 5, 553-559. [CrossRef]

68. Zhu, M.; Osakada, Y.; Kim, S.; Fujitsuka, M.; Majima, T. Black phosphorus: A promising two dimensional visible and near-infrared-activated photocatalyst for hydrogen evolution. Appl. Catal. B Environ. 2017, 217, 285-292. [CrossRef]

69. Jiang, B.; Sun, Y.; Liao, F.; Shen, W.; Lin, H.; Wang, H.; Shao, M. Rh-Ag-Si ternary composites: Highly active hydrogen evolution electrocatalysts over Pt-Ag-Si. J. Mater. Chem. A 2017, 5, 1623-1628. [CrossRef]

(C) 2020 by the authors. Licensee MDPI, Basel, Switzerland. This article is an open access article distributed under the terms and conditions of the Creative Commons Attribution (CC BY) license (http://creativecommons.org/licenses/by/4.0/). 